\title{
Analysis of Truck Downtimes Using Log Dispersion Plot*
}

\author{
V. A. Temeng and P. A. Eshun
}

Temeng V. A. and Eshun P. A. (2008). “Analysis of Truck Downtimes Using Log Dispersion Plot”, Ghana

Mining Journal, pp. 14 - 18.

\begin{abstract}
It is becoming increasingly clear that improved equipment availability is a key to optimising return on mine investment. Well-maintained equipment is safe and provides reliability to protect the operator as well as the equipment. Unplanned downtimes conflict with this maintenance function and result in costs to a mine in various causes. To minimise the occurrence of unplanned downtime, data should be recorded in logical and easily understood format which will enhance management decision making. This paper uses log dispersion plot to analyse downtimes of a fleet of 22 dump trucks from the Nchanga Open Pit, Zambia over a period of two months. Downtimes were categorised into breakdown codes to determine which ones were acute, chronic or a combination of both. The breakdown codes which were critical to the reduction of unplanned downtime and improvement of truck performance were prioritised.
\end{abstract}

\section{Introduction}

Maintenance cost which ranges between 40 and 55\% (Knights, 1999) of total mining operating cost constitutes a key parameter in an attempt to reduce cost and optimise return on investment. There is increased awareness that improved equipment availability is a key to optimising the return on mine investment. The most important function of maintenance is to provide the lowest possible cost to a mine in terms of maintenance labour, material and production loss in a safe operating condition resulting from a maintenance programme (Bise, 1992; Knights 1999; McIndoo, 1990). A wellmaintained equipment is safe and provides reliability to protect the operator as well as the equipment.

Unplanned downtimes conflict with this maintenance function and result in costs to a mine due to production losses; time lost traveling to and from equipment; delays in obtaining labour, spare parts, tools or workshop space; possible restrictions in accessing equipment components due to circumstances of breakdown; overtime; and foregone planned maintenance on other equipment due to reassignment of maintenance resources. To minimise the occurrence of unplanned downtime, data should be recorded in logical and easily understood format which will enhance management decision making (McHattie and El-Alfy, 1992). The mining industry has not attached much importance to equipment downtime information as information is often not properly recorded and preserved.

The traditional approach to analysing unplanned equipment downtimes has been to plot histograms of downtime categorised by breakdown (failure) code. Recently, log dispersion plots have been proposed for the analysis of unplanned equipment downtimes. This method allows unplanned equipment breakdown data to be analysed in a format which facilitates decision making. This paper presents an analysis of unplanned truck downtime data of a fleet of 22 dump trucks from Nchanga Open Pit, Zambia using log dispersion plot.

\section{Data Collection and Analysis}

The unplanned downtime data was extracted from the records of a computerised mine maintenance management system at Nchanga Open Pit, Zambia over a period of two months. The loading and hauling operations of the open pit comprised 7 power shovels and 84 diesel-electric dump trucks of 120 and 100 tonne capacities. The major components of the trucks are generator, exciter, electrical equipment blower, electric control system, two direct current wheel motors and dynamic resistors. The exciter is connected to the direct-current generator (which directly energises the exciter) which is connected in series with the wheel motors. The data was taken on 22 of the 100 tonne capacity trucks.

The maintenance management system contained records including the truck identification number, downtime start date and time, and end date and time from which the length of repair (downtime) is calculated, work order number and the status message describing the type of downtime. The same types of downtimes were identified for each truck and the corresponding lengths of downtimes recorded. The data was therefore categorised into downtime types. A total of 503 downtime types

\footnotetext{
* Manuscript received January 21, 2008

Revised version accepted November 14, 2008
} 
were recorded and for each type the lengths of time (in minutes) were recorded in MS Excel for all the 22 trucks over the two months period, resulting in a total of 2329 downtime events. To make the data wieldy and facilitate analysis the downtime types were categorised into 15 breakdown codes based mainly on major truck components and operational delays associated with shortages and lack of spares. Table 1 presents a description of the various breakdown codes.

To facilitate further analysis of the data the number of repairs, Mean Time to Repair (MTTR), du- ration and percentage of total duration were determined for each breakdown code. A summary of this data is presented in Table 2.

\section{The Log Dispersion Plotting Method}

According to Knights (1999) maintenance downtime is the product of two factors: the frequency of breakdowns in a particular breakdown code and the associated MTTR. In order to determine those breakdowns that contribute to unplanned downtimes, the log dispersion plots enable breakdowns to be classified into whether they are acute

Table 1 Description of Truck Breakdown Codes

\begin{tabular}{|l|l|c}
\hline Truck Component & \multicolumn{1}{|c}{ Description } & Breakdown Code \\
\hline Engine & All engine types of breakdowns & A \\
\hline Transmission & Faults Associated with gear and gear selector & C \\
\hline Electric Drive & $\begin{array}{l}\text { Faults associated with generator, electric control and wheel } \\
\text { motors }\end{array}$ & D \\
\hline Tyre & Faults associated with all tyres and rims & E \\
\hline Body/Deck & $\begin{array}{l}\text { Faults associated with main deck, extension ladder, pan, } \\
\text { bonnet, hand rails, rock ejector }\end{array}$ & F \\
\hline Cab & $\begin{array}{l}\text { Faults associated with driver's cab including doors, gauges, } \\
\text { seat, windshield }\end{array}$ & $\mathrm{G}$ \\
\hline Frame & $\begin{array}{l}\text { Faults associated with bumper, main support members, drive } \\
\text { axle mounting, drive axle alignment, engine mount }\end{array}$ & $\mathrm{H}$ \\
\hline Braking & $\begin{array}{l}\text { Faults associated with emergency, parking, dynamic and } \\
\text { service brakes }\end{array}$ & $\mathrm{I}$ \\
\hline Cooling & Faults associated with water and oil cooling systems & $\mathrm{J}$ \\
\hline Suspension & Faults associated with front and rear suspension systems & $\mathrm{L}$ \\
\hline Hydraulics & $\begin{array}{l}\text { Faults associated with hydraulic steering, reservoir, filtration, } \\
\text { suction, hoist, pumps, valves and tubes }\end{array}$ & \\
\hline Fuel & Faults associated with diesel fuel system & $\mathrm{M}$ \\
\hline Electrical System & Faults associated with battery, lighting and cables & $\mathrm{N}$ \\
\hline Air System & $\begin{array}{l}\text { Faults associated with air system including main reservoir, } \\
\text { compressor, cleaner, etc. }\end{array}$ & $\mathrm{O}$ \\
\hline Operational & operational delays associated with shortages and lack of spares & \\
\hline
\end{tabular}

Table 2 Summary of Downtime Data

\begin{tabular}{|c|c|c|c|c|}
\hline Breakdown Code & No. of repairs & MTTR (min) & $\begin{array}{c}\text { Duration (min) } \\
\text { MTTR } \times \text { No. of repairs }\end{array}$ & Percent \\
\hline A & 498 & 229.95 & 114515 & 22.94 \\
\hline C & 206 & 354.28 & 72981 & 14.62 \\
\hline K & 295 & 178.42 & 52634 & 10.54 \\
\hline M & 361 & 139.12 & 50223 & 10.06 \\
\hline I & 259 & 166.92 & 43233 & 8.66 \\
\hline D & 19 & 2189.63 & 41603 & 6.33 \\
\hline H & 204 & 159.63 & 32565 & 5.52 \\
\hline E & 191 & 146.29 & 27941 & 3.46 \\
\hline G & 85 & 203.36 & 17286 & 2.99 \\
\hline N & 13 & 1147.46 & 14917 & 2.86 \\
\hline L & 91 & 157.10 & 14296 & 1.44 \\
\hline F & 35 & 206.11 & 7214 & 1.13 \\
\hline J & 53 & 106.79 & 5660 & 0.62 \\
\hline B & 9 & 341.33 & 3072 & 0.23 \\
\hline
\end{tabular}


(requiring substantial repair time), chronic (excessive breakdown frequency) or a combination of both. The plot provides a detailed representation of the breakdown patterns of equipment, facilitating the diagnosis of root cause of breakdowns and providing useful information on optimum stock levels of spares. In addition, the plot enables better prioritisation of maintenance problems which enable a more effective utilisation of limited maintenance resources.

To obtain a log dispersion plot, the total downtime of a breakdown code, $\mathrm{i}$, is considered as Cost $\mathrm{i}_{\mathrm{i}}$ which is given as (Knights, 1999):

$$
\text { Cost }_{\mathrm{i}}=n_{i} \times \operatorname{MTTR}_{i}
$$

where $n_{i}$ is the number of unplanned downtimes associated with code $\mathrm{i}$ and $\mathrm{MTTR}_{\mathrm{i}}$ is the mean time to repair code $\mathrm{i}$.

Taking the logarithm of Equation 1 becomes:

$\log \left(\right.$ Cost $\left._{\mathrm{i}}\right)=\log \left(n_{i}\right)+\log \left(\right.$ MTTR $\left._{i}\right)$

A log dispersion plot is a graph of $\log \left(\mathrm{MTTR}_{\mathrm{i}}\right)$ against $\log \left(\mathrm{n}_{\mathrm{i}}\right)$. From the log dispersion plot, repairs necessitating lengthy mean repair times $\left(\mathrm{MTTR}_{\mathrm{i}}\right)$ are considered as acute problems. Those breakdown codes with high frequency of occurrence $\left(\mathrm{n}_{\mathrm{i}}\right)$ are considered as chronic problems and those breakdown codes with lengthy mean time to repair and high frequency of occurrence are both acute and chronic problems. The log dispersion plot can be partitioned into four quadrants if threshold values for MTTR and $\mathrm{n}$ are determined. The upper quadrants represent acute breakdowns, the right hand quadrants represent chronic breakdowns hence the upper right hand quadrant represents a region of acute and chronic breakdowns (Knights, 1999). The lower left hand quadrant is the quadrant with neither acute nor chronic breakdowns. This constitutes the least problematic quadrant for breakdowns in terms of the frequency and the MTTR.

\subsection{Determining the Threshold Values}

According to Knights (1999) threshold values can either be absolute values, determined by company policy, or relative values which depend on the relative magnitudes and the quantity of breakdown data. One approach for determining the threshold values based on the magnitude and quantity of breakdown data is presented.

The total downtime, D, consumed by unplanned breakdown is given by:

$$
D=\sum d_{i}
$$

where $d_{i}$ is the total downtime due to breakdown code i. The total number of breakdowns, $\mathrm{N}$, is given by:

$N=\sum n_{i}$

If $\mathrm{Q}$ is the number of distinct breakdown codes used to categorise the repair data, the threshold limit for acute breakdowns (Limit ${ }_{\text {MTTR }}$ ) can be defined as:

$$
\text { Limit }_{\text {MTTR }}=\frac{D}{N}
$$

and the threshold limit for chronic breakdowns ( Limit $_{n}$ ) can be defined as:

$$
\text { Limit }_{\mathrm{n}}=\frac{N}{Q}
$$

\section{Results and Analysis}

Fig. 1 is a log dispersion plot of the downtime data of the 22 dump trucks based on Table 2 and Equation 2. To determine the threshold values which were used to divide the log dispersion plot into four quadrants, figures from Table 2 were substituted in Equations 3 to 6. From Table 2, D = 499 280 minutes, $\mathrm{N}=2329$ and $\mathrm{Q}=15$. Therefore, the threshold limit value for acute downtimes ( Limit $_{\text {MTTR }}$ ) is 499 280/2 $329=214.4$ minutes and that for chronic downtimes $\left(\mathrm{Limit}_{\mathrm{n}}\right)$ is $2329 / 15=$ 155.3 minutes.

A frequency plot of downtime duration is also presented in Fig. 2. Table 3, which was extracted from Fig. 1 shows the various breakdowns which are chronic, acute, or acute and chronic.

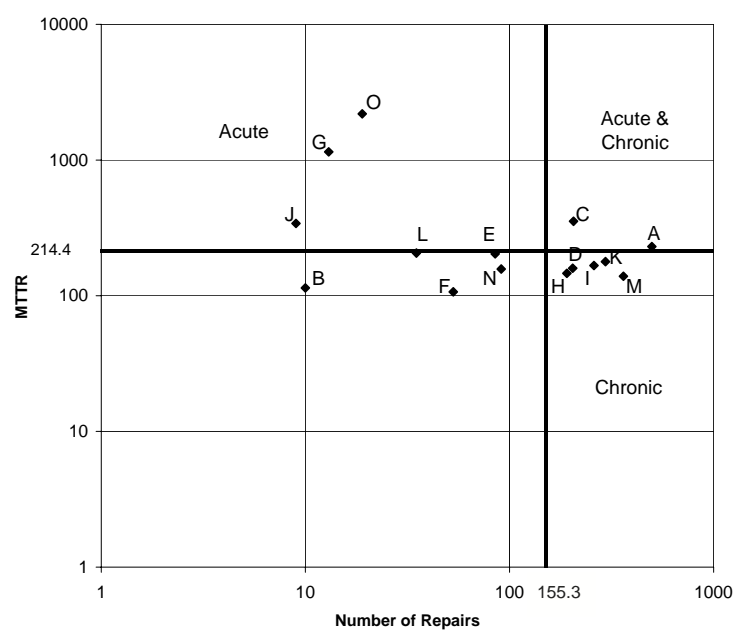

Fig. 1 Log Dispersion Plot of the Breakdown Data for the 22 Trucks

Chronic breakdowns result from the following categories: tyre, braking, cooling, hydraulics and electrical system. These are the most frequently occurring and are normally associated with com- 
ponent quality defects, equipment design problems, inappropriate operator practices or poor quality control in upstream operations. For instance breakdowns associated with tyres may depend on the tyre material quality, adherence to operating standards like tyre inflation pressure and tonne kilometer per hour thresholds and condition of the bench floor. Acute breakdowns may be associated with difficulty in accessing component, difficulty in diagnosing component and unusually long delays due to lack of planning.

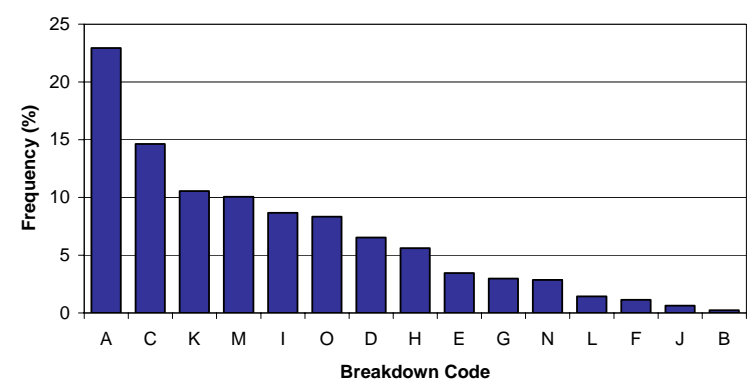

Fig. 2 Histogram of Unplanned Truck Downtime Prioritised by Duration

To reduce truck downtime significantly the downtimes in the acute, and acute and chronic quadrants offer the best opportunity, since they constitute the highest set of mean time to repair. This falls in line with the recommendation by Bahrami-G and Price (1999) that to optimise maintenance the failures that contribute $75 \%$ of time should be given the highest priority attention, the next $20 \%$ the second priority and the last $5 \%$ the lowest priority. In this case, with reference to Table 3 , the five downtime categories in the acute, and acute and chronic breakdown categories, which are engine, electric drive, frame, suspension and delays, constitute $73 \%$ of the total MTTR. In fact, if maintenance action is taken to reduce the number of repairs of each of the five downtime categories in these two breakdown categories by only one (ie. 5 repairs out of a total of 2329 ) the system will benefit by a saving of 4262.7 minutes, which is equivalent to $0.9 \%$ of the time lost from unplanned downtimes. The chronic breakdowns which constitute $13 \%$ of MTTR and $41 \%$ of duration should be given second priority attention.

Delays with a breakdown code of O, constituted the highest value of $37.5 \%$ of total MTTR. This implies that downtimes associated with delays due to lack of spares and shortages are critical in improving unplanned downtimes of the 22 trucks. Lack of spares and shortages suggest that the spares and supplies inventory management system of the mine may be inefficient or the coordination and communication between the stores, maintenance department and production department may be lacking. An inefficient spares and supplies inventory management system appears to be more likely based on the length of times involved.

Once the various unplanned breakdowns are prioritised, the next step is to identify the root causes of breakdowns, identify measures to reduce downtimes or reduce the frequency of breakdowns in order to increase availability. Analysis of break-

Table 3 Breakdown Categories Based on Log Dispersion Plot

\begin{tabular}{|c|c|c|c|c|c|}
\hline $\begin{array}{c}\text { Breakdown } \\
\text { Code }\end{array}$ & Truck Component & No. of repairs & MTTR & $\begin{array}{c}\text { Duration } \\
\text { MTTR } \times \text { No. of repairs }\end{array}$ & Percent \\
\hline \multicolumn{6}{|c|}{ Acute and Chronic Breakdowns } \\
\hline A & Engine & 498 & 229.95 & 114515 & 22.94 \\
\hline $\mathrm{C}$ & Electric Drive & 206 & 354.28 & 72981 & 14.62 \\
\hline Subtotal & & & 584.23 & 187496 & \\
\hline \multicolumn{6}{|c|}{ Acute Breakdowns } \\
\hline $\mathrm{G}$ & Frame & 13 & 1147.46 & 14917 & 2.99 \\
\hline $\mathrm{J}$ & Suspension & 9 & 341.33 & 3072 & 0.62 \\
\hline $\mathrm{O}$ & Operational & 19 & 2189.63 & 41603 & 8.33 \\
\hline Subtotal & & & 3678.42 & 59592 & \\
\hline \multicolumn{6}{|c|}{ Chronic Breakdowns } \\
\hline $\mathrm{D}$ & Tyre & 204 & 159.63 & 32565 & 6.52 \\
\hline $\mathrm{H}$ & Braking & 191 & 146.29 & 27941 & 5.60 \\
\hline $\mathrm{I}$ & Cooling & 259 & 166.92 & 43233 & 8.66 \\
\hline $\mathrm{K}$ & Hydraulics & 295 & 178.42 & 52634 & 10.54 \\
\hline $\mathrm{M}$ & Electrical System & 361 & 139.12 & 50223 & 10.06 \\
\hline Subtotal & & & 790.38 & 206596 & \\
\hline \multicolumn{6}{|c|}{ Other Breakdowns } \\
\hline $\mathrm{B}$ & Transmission & 10 & 114.00 & 1140 & 0.23 \\
\hline $\mathrm{E}$ & Body/Deck & 85 & 203.36 & 17286 & 3.46 \\
\hline $\mathrm{F}$ & $\mathrm{Cab}$ & 53 & 106.79 & 5660 & 1.13 \\
\hline $\mathrm{L}$ & Fuel & 35 & 206.11 & 7214 & 1.44 \\
\hline $\mathrm{N}$ & Air System & 91 & 157.10 & 14296 & 2.86 \\
\hline Subtotal & & & 787.36 & 45596 & \\
\hline Grand Total & & & 5840.39 & 499280 & \\
\hline
\end{tabular}


downs to determine the root cause requires that all information pertaining to a component and its breakdown (failure) be collected and analysed (McHattie and El-Alfy, 1992). Determining the root cause of failures requires the combined effort of both experienced maintenance and operating personnel. Root cause of breakdowns could be analysed under areas like inspection, maintenance, operational, design, material quality or maintenance resource problems. Following the determination of the root causes for each breakdown the necessary action could be taken to minimise the duration and frequency of occurence.

\section{Conclusion}

A Log dispersion plot has been used to analyse the downtimes of 22 dump trucks. The breakdown codes in the acute, and acute and chronic categories were found to be the ones that contributed most to the reduction of downtime and therefore should be given the highest priority in improving the performance of trucks. Chronic breakdowns should be given the second priority, in this regard.

It should be noted that the successful application of log dispersion plots to analyse breakdown data is dependent on the availability of sufficient downtime data of good quality. In spite of the cost (in terms of time and money) of recording and storing such data, such analysis to improve on the performance of equipment will justify the investment.

\section{References}

Bahrami-G, K. and Price, J. (1999), "Risk-Based Maintenance”, Maintenance Journal, Vol. 12, No. 4, pp. 24 - 29.

Bise, C. J. (1992), "Equipment Maintenance", SME Mining Engineering Handbook, $2^{\text {nd }}$ ed, Vol 1, Society for Mining, Metallurgy and Exploration Incorporated, Littleton, pp. 1260 - 1269.

Knights, P. F. (1999), “Analysing Breakdowns”, Mining Magazine, Vol. 181, No. 3, pp. 165 $-171$.

McHattie, L. and El-Alfy, S. E. (1992), "Maintenance Improvements through the Introduction of Reliability Concepts" CIM Bulletin, Vol. 84, No. 964, pp. 47 - 54

McIndoo, R. M. (1990), "Maintenance Systems", Surface Mining, $2^{\text {nd }}$ ed, Society for Mining, Metallurgy and Exploration Incorporated, Littleton, pp. 922 - 934.

\section{Authors}

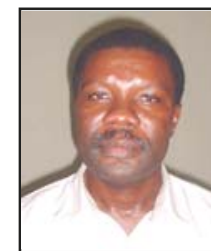

V. A. Temeng is a Senior Lecturer in Mining Engineering at the University of Mines and Technology, Tarkwa. He obtained his BSc (Hons.) and Postgraduate Diploma in Mining Engineering degrees from the University of Mines and Technology in 1985 and 1986 respectively. He obtained his MSc degree from the University of Zambia in 1992 and his PhD degree from the Michigan Technological University, USA in 1997. He joined the University as a Lecturer in 1990. His areas of specialisation include Operations Research, Materials Handling and Computer Applications.

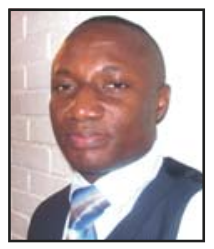

P. A. Eshun obtained his BSc (Hons), Postgraduate Diploma (PgD) and MPhil degrees in Mining Engineering from the Kwame Nkrumah University of Science and Technology, School of Mines, Tarkwa, Ghana (now University of Mines and Technology, Tarkwa, Ghana) in 1998, 1999 and 2001 respectively. He has been a lecturer in Mining Engineering at the University of Mines and Technology, Tarkwa since 2002. He lectures in Computer Applications, Mine Management, Mineral Economics and Mineral Project Evaluation. His main research areas are in Project Management, Mine Finance, Economic Evaluation and Risk Analysis. He is currently a Senior Lecturer and the University Training Coordinator. 